УДК 658.155:519.237.7

\author{
Чернишова О.Б. \\ кандидат економічних наук, доцент \\ кафедра фрінансів \\ Одеський інститут фінансів Українського державного \\ університету фінансів та міжнародної торгівлі \\ вул. 25 Чапаєвської дивізії, 6, м. Одеса, Україна, 65070 \\ E-mail: chernyshova_o@ukr.net,
}

\title{
Янковий В.O.
}

кандидат економічних наук, старший викладач

кафедра економіки та управління національним господарством

Одеський національний економічний університет

вул. Преображенська, 8, м. Одеса, Україна, 65082

E-mail: vladimir ya@ukr.net

\section{ТЕОРЕТИЧНІ ЗАСАДИ ФАКТОРНОГО АНАЛІЗУ ПРИБУТКУ ПІДПРИЄМСТВА НА БАЗІ ДЕТЕРМІНОВАНИХ МОДЕЛЕЙ}

Обговорюються теоретико-методологічні питання застосування детермінованих моделей мультиплікативного типу в процесі розкладання абсолютного і відносного приросту прибутку підприємства за факторами. Розглядаються два основні класи мультиплікативних моделей - статистичні та математичні. Зокрема, аналізуються методи ланцюгових підстановок, виявлення ізольованого впливу факторів, досліджується диференційний, інтегральний і логарифмічний методи. Проводиться порівняння їх переваг і недоліків, а також даються рекомендації щодо впровадження в практику фінансовоекономічного аналізу на підприємстві методу виявлення ізольованого впливу факторів і логарифмічного методу.

Ключові слова: детерміновані мультиплікативні моделі, метод ланцюгових підстановок, метод виявлення ізольованого впливу факторів.

Постановка проблеми та її зв'язок з важливими науковими та практичними завданнями. При дослідженні впливу окремих чинників на зміну прибутку підприємства, зазвичай, використовуються різноманітні моделі зв'язків, які за характером причинно-наслідкових залежностей, що постулюються між змінними, можна умовно розділити на два класи: імовірнісні та детерміновані.

В основі імовірнісних моделей лежить передумова про стохастичний (кореляційний або регресійний) зв'язок між величиною прибутку підприємства і факторами, що іiі обумовлюють. Тобто поряд 3 головними вирішальними чинниками розглядаються також й другорядні та випадкові причини, що визначають варіацію прибутку в просторі та часі. Це досить реальна постановка задачі, оскільки в економіч- ній дійсності діє саме такий механізм формування рівня беззбитковості суб'єкта господарювання.

Але слід зауважити, що згідно закону великих чисел $з$ математичної статистики для успішної побудови ймовірнісних моделей будь-яких економічних показників, в тому числі й прибутку, необхідна достатня інформаційна база у вигляді великої за об'ємом сукупності спостережень $N$. В протилежному випадку (на малих вибірках) стохастичні залежності між змінними не зможуть проявитися в явному вигляді. Цей факт є основною причиною, за якою дані моделі майже не використовуються в фінансовоекономічному аналізі, оскільки дослідник зазвичай володіє інформацією всього за 2-3 періоди - за звітний рік і базисний (плановий).

Детерміновані моделі, зокрема, адитивні

та мультиплікативні

$$
\begin{aligned}
& Y=\sum_{j=1}^{m} X_{j}=X_{1}+X_{2}+\ldots+X_{m} \\
& Y=\prod_{j=1}^{m} X_{j}=X_{1} \times X_{2} \times \ldots \times X_{m}
\end{aligned}
$$

базуються на передумові про те, що варіація результативної ознаки $Y$ (прибутку) функціонально обумовлюється дією декількох невипадкових факторів. Це означає, що при відомих значеннях чинників величина залежної змінної визначається однозначно, тобто 3 вірогідністю 1. Хоча вказана гіпотеза й не зовсім аде- 
кватна реальній економічній дійсності, але вона дозволяє будувати детерміновані моделі факторного аналізу лише на двох спостереженнях, оскільки функціональні зв'язки проявляються в кожному окремому випадку, для кожного об'єкта дослідження.

Однак слід мати на увазі, що при застосуванні мультиплікативних моделей (2) виникає методологічна проблема розкладання загального приросту результативної ознаки $\Delta Y$ за факторами внаслідок наступних розміркувань. Справа в тім, що мультипліка- тивна залежність передбачає наявність поряд з адитивним ефектом впливу чинників $X_{1}, X_{2}, \ldots, X_{\mathrm{m}}$ на $Y$ також і додаткового ефекту взаємодії цих факторів. Цей додатковий вплив зазвичай пояснюється синергетичним ефектом взаємодії зміни чинників, що аналізуються.

Наприклад, якщо постулюється простіша модель $Y=X_{1} \times X_{2}$, то приріст $\Delta Y$ за період часу $\Delta t=t_{1}-$ $t_{0}$ виражається наступною формулою:

$$
\Delta Y=X_{10} \Delta X_{2}+X_{20} \Delta X_{1}+\Delta X_{1} \Delta X_{2},
$$

де $\Delta X_{1}, \Delta X_{2}-$ прирости чинників;

$X_{10}, X_{20}$ - базисні значення чинників;

$t_{0}, t_{1}$ - відповідно базисний і звітний періоди часу.

В зв'язку з цим виникає питання: до впливу якого фактора віднести величину $\Delta X_{1} \Delta X_{2}$ ? Вона, як раз, і представляє собою згадану вище величину взаємодії основних чинників $X_{1}, X_{2}$. А може іiі треба розглядати виокремлено, тобто не відносити до жодного 3 вихідних факторів? Слід констатувати, що поставлені методологічні питання не мають однозначної і чіткої відповіді в сучасній економічній літературі.

Аналіз останніх публікацій з проблеми показав, що більшість науковців використовують на практиці саме мультиплікативні детерміновані моделі в якості основного інструменту факторного фінансово-економічного аналізу прибутку на інших показників результативності сучасного виробництва [1-5].

Наприклад, В.I. Осипов запропонував три види мультиплікативних моделей прибутку, які відрізняються одна від одної ступенем деталізації чинників, що знаходяться в їх правих частинах [6, с. 155 ]:

1. Модель прибутку, до складу якої входять чотири агрегованих фактори: 1) середня чисельність робітників виробничо-промислового персоналу; 2) продуктивність праці; 3) коефіцієнт реалізації продукції (відношення реалізованої продукції до виробленої товарної продукції за даний період); 4) прибуткомісткість реалізованої продукції.

2. Модель прибутку, до складу якої входять п’ять дезагрегованих чинників: 1) середня чисельність робітників виробничо-промислового персоналу; 2) фондоозброєність праці; 3) фондовіддача; 4) коефіцієнт реалізації продукції; 5) прибуткомісткість реалізованої продукції.

3. Модель прибутку, до складу якої входять сім деталізованих чинників: 1) середня чисельність робітників виробничо-промислового персоналу; 2) фондоозброєність праці; 3) частка активної частини основних виробничих фондів; 4) питома виробнича потужність; 5) коефіцієнт використання виробничої потужності; 6) коефіцієнт реалізації продукції; 7) прибуткомісткість реалізованої продукції.

Формулювання цілей дослідження. Мета даної статті - викласти теоретико-методологічні підходи щодо найбільш ефективного використання різ- номанітних детермінованих моделей в процесі факторного аналізу прибутку на підприємстві, які засновані на мультиплікативній формі зв'язку між результативною ознакою і чинниками, що ії визначають.

Виклад основних результатів та їх обгрунтування. На даний момент усе розмаїття запропонованих підходів до розкладання загального приросту результативної ознаки за чинниками при використанні в факторному фінансово-економічному аналізі мультиплікативних моделей типу (2) можна умовно поділити на дві групи: 1) статистичні; 2) математичні.

Не втрачаючи загальності, розглянемо їх переваги та недоліки на прикладі чотирьохфакторної моделі, яку для простоти представимо у вигляді $Y=$ $a \times b \times c \times d$. Почнемо зі статистичних методів вирішення даної проблеми як історично перших і найбільш популярних у факторному фінансово-економічному аналізі.

Серед них виділяються два основних напрямки, котрі включають декілька модифікацій: 1) метод ланцюгових підстановок (або метод виявлення взаємопов'язаного впливу факторів); 2) метод виявлення ізольованого впливу факторів.

Метод ланцюгових підстановок полягає в елімінуванні впливу на $Y$ всіх чинників, окрім одного. При цьому передбачається, що фактори $a, b, c, d$ змінюються не одночасно, а в певній послідовності: спочатку змінюється перший, а всі інші залишаються без зміни, потім змінюються другий і так далі при незмінності останніх. Даний метод домінує в теорії і практиці статистики та економічного аналізу всіх пострадянських країн, є основним підходом до дослідження абсолютних і відносних внесків окремих факторів у зміну результативної ознаки.

При цьому, передусім, будується індивідуальний індекс зі статистичними вагами результативної ознаки $Y$, оскільки при проведенні факторного аналізу прибутку дослідник зазвичай має справу з показниками одного підприємства за два періоду часу звітним та базисним (плановим). Він має наступний вигляд: 


$$
3_{Y}=\frac{Y_{1}}{Y_{0}}=\frac{a_{1} b_{1} c_{1} d_{1}}{a_{0} b_{0} c_{0} d_{0}}
$$

Метод ланцюгових підстановок виходить 3 того, що ознака $a є$ первинною, об'ємною, вираженою абсолютною величиною. Ознака $b \in$ вторинною по відношенню до $a$, але первинною по відношенню до $c$. Ознака $c \in$ вторинною по відношенню до $b$, але первинною по відношенню до $d$. Фактори $b$ і $c$ часто $\epsilon$ відносними величинами структури, відображають питому вагу даних економічних показників в деякому середовищі. Фактор $d$ - зазвичай якісний відносний показник.

Таким чином, ця система відображає економічну гіпотезу про першочергову зміну первинної по відношенню до всіх інших об'ємної ознаки $a$. Наступні зміни всіх інших ознак відбуваються з урахуванням її зміни і т.д.

При цьому факторні індекси будуються за такою схемою:

$$
3_{a}=\frac{a_{1} b_{0} c_{0} d_{0}}{a_{0} b_{0} c_{0} d_{0}} ; \quad 3_{b}=\frac{a_{1} b_{1} c_{0} d_{0}}{a_{1} b_{0} c_{0} d_{0}} ; \quad 3_{c}=\frac{a_{1} b_{1} c_{1} d_{0}}{a_{1} b_{1} c_{0} d_{0}} ; \quad 3_{d}=\frac{a_{1} b_{1} c_{1} d_{1}}{a_{1} b_{1} c_{1} d_{0}} .
$$

Іншими словами, фактори, вплив яких уже враховано, фіксуються у чисельнику та знаменнику індексу на звітному рівні, а чинники, внесок яких ще належить виміряти, - на базисному рівні.

Оскільки чисельник першого індексу в системі (5) збігається зі знаменником другого індексу, а чисельник другого індексу збігається зі знаменником третього індексу і т.д., утворюючи ланцюжок (звідки й назва методу), то для даного методу справедливе співвідношення:

$$
i_{Y}=i_{a} \times i_{b} \times i_{c} \times i_{d}
$$

Загальний абсолютний приріст результативної ознаки $\Delta Y$, а також частинні прирости за рахунок кожного фактора $\left(\Delta Y_{a}, \Delta Y_{b}, \Delta Y_{c}, \Delta Y_{d}\right)$ знаходяться як різниця між чисельником і знаменником відповідних індексів моделі (4), (5). При цьому легко показати, що виконується балансове співвідношення

$$
\Delta Y=\Delta Y_{a}+\Delta Y_{b}+\Delta Y_{c}+\Delta Y_{d}=a_{1} b_{1} c_{1} d_{1}-a_{0} b_{0} c_{0} d_{0}
$$

Відносні прирости визначаються шляхом ділення відповідних абсолютних приростів на базисний рівень результативної ознаки $Y_{0}=a_{0} b_{0} c_{0} d_{0}$. 3 формули (7) випливає, що при застосуванні методу ланцюгових підстановок сума частинних відносних приростів $\Delta Y_{a} / Y_{0}+\Delta Y_{b} / Y_{0}+\Delta Y_{c} / Y_{0}+\Delta Y_{d} / Y_{0}$ дорівнює загальному відносному приросту $\Delta Y / Y_{0}$.

Збіг порядку утворення факторних індексів (5) 3 правилами побудови зведених індексів, прийнятими в українській статистиці, а також виконання балансового співвідношення (7) вважається головними перевагами методу ланцюгових підстановок у порівнянні з усіма іншими підходами до факторного індексного аналізу прибутку.

Слід зазначити, що в економічній практиці можна зустріти декілька різновидів даного способу розкладання загального абсолютного (відносного) приросту результативної ознаки $\Delta Y$ за факторами. Серед них найбільш відомими є метод абсолютних різниць, метод відносних різниць, метод процентних різниць.

Метод ланцюгових підстановок (або метод виявлення взаємопов'язаного впливу факторів у всіх його різновидах та модифікаціях) поряд з перевагами має істотні недоліки. Справа в тім, що в реальній економічній дійсності чинники діють одночасно, спільно, і в результаті їх взаємодії з'являється ефект у вигляді додаткового приросту результативного показника (див. вираження (3)), який приєднується до всіх чинників, окрім першого. У зв'язку з цим вплив кожного фактора на зміну результативного показника міняється залежно від місця, на яке він поставлений дослідником в детермінованій моделі. Внаслідок цього в алгоритмі методу ланцюгових підстановок необгрунтовано викривляється вплив усіх чинників, окрім першого об'ємного фактора $a$.

Другий статистичний метод (виявлення ізольованого впливу факторів на $Y$ ) певним чином долає даний недолік. Він виходить з передумови, що при 
побудові індексної факторної системи змінюється рівні: один із факторів, а решта фіксуються на базисному

$$
3_{a}=\frac{a_{1} b_{0} c_{0} d_{0}}{a_{0} b_{0} c_{0} d_{0}} ; 3_{b}^{3}=\frac{a_{0} b_{1} c_{0} d_{0}}{a_{0} b_{0} c_{0} d_{0}} ;{ }_{c}^{3}=\frac{a_{0} b_{0} c_{1} d_{0}}{a_{0} b_{0} c_{0} d_{0}} ; 3_{d}^{3}=\frac{a_{0} b_{0} c_{0} d_{1}}{a_{0} b_{0} c_{0} d_{0}} .
$$

Як видно з формул (8), вимірювання внеску кожного фактора в приріст результативного економічного показника $\Delta Y$ не залежить від послідовності виявлення впливу інших чинників, тобто відбувається ізольовано, що й зумовило назву даного методу індексного аналізу.
Наведемо формули розрахунку абсолютних частинних приростів результативної ознаки $Y$ за рахунок кожного з чотирьох чинників при використанні методу виявлення ізольованого впливу факторів:

$$
\begin{aligned}
& \Delta Y_{a}=a_{1} b_{0} c_{0} d_{0}-a_{0} b_{0} c_{0} d_{0} \\
& \Delta Y_{b}=a_{0} b_{1} c_{0} d_{0}-a_{0} b_{0} c_{0} d_{0} \\
& \Delta Y_{c}=a_{0} b_{0} c_{1} d_{0}-a_{0} b_{0} c_{0} d_{0} \\
& \Delta Y_{d}=a_{0} b_{0} c_{0} d_{1}-a_{0} b_{0} c_{0} d_{0}
\end{aligned}
$$

3 формул (9) випливає, що для системи індексів (4), (9) співвідношення (7) не виконується, тому в мультиплікативну модель вводиться додатковий п'я- тий фактор $e$, який є взаємодією перших чотирьох (основних) чинників $a, b, c, d$. Його абсолютний внесок знаходиться за остаточним принципом

$$
\Delta Y_{e}=\Delta Y-\left(\Delta Y_{a}+\Delta Y_{b}+\Delta Y_{c}+\Delta Y_{d}\right)
$$

Таким чином, метод виявлення ізольованого впливу факторів дозволяє виділити внесок взаємодії основних факторів (ознаки $e$ ), який в методі ланцюгових підстановок приєднується до вкладу всіх факторів, окрім об'ємного чинника $a$. Даний факт вважається одною з серйозних переваг методу виявлення ізольованого впливу факторів у порівнянні з методом ланцюгових підстановок. Такий підхід забезпечує виконання наступних умов при розкладанні абсолютного (відносного) приросту результативної ознаки за факторами:

1) визначення істинного внеску кожного основного чинника в приріст результативної ознаки $\Delta Y$

2) виділення в явному вигляді ефекту взаємодії основних чинників $\left(\Delta Y_{e}\right)$;
3) внесок кожного основного чинника в приріст результативної ознаки $\Delta Y$ не залежить від його місця в мультиплікативній факторній моделі.

Останнім часом з'явилося декілька нових методів розкладання абсолютного (відносного) приросту результативної ознаки за факторами, в основі яких лежить математичний апарат, зокрема методи диференціювання, інтегрування, логарифмування [7]. Розглянемо їх дещо детальніше.

Диференціальний метод полягає в наступному. Нехай $Y=f\left(X_{1}, X_{2}, \ldots, X_{\mathrm{m}}\right)$, де $f-$ функція, що диференціюється. 3 курсу математичного аналізу відомо, що абсолютний приріст результативної ознаки $\Delta Y$ представляється наступним чином:

$$
\Delta Y \approx \frac{\partial Y}{\partial X_{1}} \Delta X_{1}+\frac{\partial Y}{\partial X_{2}} \Delta X_{2}+\ldots+\frac{\partial Y}{\partial X_{m}} \Delta X_{m}
$$

$$
\begin{gathered}
\frac{\partial Y}{\partial X_{j}}-\text { перша частинна похідна результативної ознаки } Y \text { за } j \text {-м чинником } \\
\quad(j=1,2, \ldots, m) .
\end{gathered}
$$

Відзначимо, що значення всіх похідних беруться в початковій точці, тобто за значеннями змінних у базисному періоді. Отже, внесок чинника $X_{\mathrm{j}}$ в загальний приріст результативної ознаки $\Delta Y$ виглядає так:

$$
\Delta Y_{j}=\frac{\partial Y}{\partial X_{j}} \Delta X_{j}
$$


Розглянемо використання математичних методів розкладання абсолютного приросту результати- вної ознаки за факторами. В чотирьох-факторній моделі перші частинні похідні будуть мати вигляд:

$$
\frac{\partial Y}{\partial a}=b_{0} c_{0} d_{0} ; \quad \frac{\partial Y}{\partial b}=a_{0} c_{0} d_{0} ; \quad \frac{\partial Y}{\partial c}=a_{0} b_{0} d_{0} ; \quad \frac{\partial Y}{\partial d}=a_{0} b_{0} c_{0} .
$$

По визначенню $\Delta Y=Y_{1}-Y_{0}$. Отже, отримаємо таке вираження внеску кожного чинника:

$$
\begin{aligned}
\Delta Y_{a} & =\frac{\partial Y}{\partial a} \Delta a=b_{0} c_{0} d_{0}\left(a_{1}-a_{0}\right)=a_{1} b_{0} c_{0} d_{0}-a_{0} b_{0} c_{0} d_{0} \\
\Delta Y_{b} & =\frac{\partial Y}{\partial b} \Delta b=a_{0} c_{0} d_{0}\left(b_{1}-b_{0}\right)=a_{0} b_{1} c_{0} d_{0}-a_{0} b_{0} c_{0} d_{0} \\
\Delta Y_{c} & =\frac{\partial Y}{\partial c} \Delta c=a_{0} b_{0} d_{0}\left(c_{1}-c_{0}\right)=a_{0} b_{0} c_{1} d_{0}-a_{0} b_{0} c_{0} d_{0} \\
\Delta Y_{d} & =\frac{\partial Y}{\partial d} \Delta d=a_{0} b_{0} c_{0}\left(d_{1}-d_{0}\right)=a_{0} b_{0} c_{0} d_{1}-a_{0} b_{0} c_{0} d_{0}
\end{aligned}
$$

диференціального методу. Нехай, як і в попередньому випадку, для функції $Y=f\left(X_{1}, X_{2}, \ldots, X_{\mathrm{m}}\right)$, що диференціюється, виконується співвідношення (11), а чинники змінюються на деякій траєкторії $L$ рівномірно або рівно прискорено, тобто в лінійній або по параболічній залежності від часу.

Якщо розділити весь інтервал зміни чинників на $n$ відрізків, то формула (11) прийме вигляд:

Інтегральний метод $є$ логічним розвитком

$$
\Delta Y \approx \sum_{i=1}^{n} f_{1}^{\prime} \Delta_{i 1}+\sum_{i=1}^{n} f_{2}^{\prime} \Delta_{i 2}+\ldots+\sum_{i=1}^{n} f_{m}^{\prime} \Delta_{i m}
$$

Здійснюватимемо дроблення інтервалу на всю більшу кількість відрізків, всякий раз перераховуючи частинні похідні і беручи кожного разу їх значення в початковій точці, тобто за значеннями змін- них у базисному періоді. При безкінечному дробленні відрізків, тобто при $n \rightarrow \infty$ суми замінюються інтегралами:

$$
\Delta Y \approx \int_{L_{1}} f_{1}^{\prime} d X_{1}+\int_{L_{1}} f_{2}^{\prime} d X_{2}+\ldots+\int_{L_{m}} f_{m}^{\prime} d X_{m}
$$

У ролі траєкторії $L$, по якій береться інтеграл, найчастіше виступає пряма лінія, тобто вважається, що фактори змінюються в часі рівномірно.

У зв'язку зі складністю обчислення деяких визначених інтегралів і додаткових проблем, пов'язаних 3 можливою дією чинників у протилежних на-

прямах, на практиці користуються наступними робочими формулами розрахунку частинних приростів результативної ознаки, для найбільш популярних факторних моделей:

- двохфакторної мультиплікативної моделі $Y=a \times b$

$$
\Delta Y_{a}=b_{0} \Delta a+\frac{\Delta a \Delta b}{2} ; \quad \Delta Y_{b}=a_{0} \Delta b+\frac{\Delta a \Delta b}{2} ;
$$


- трьохфакторної мультиплікативної моделі $Y=a \times b \times c$

$$
\begin{aligned}
& \Delta Y_{a}=\frac{1}{2} \Delta a\left(b_{0} c_{1}+b_{1} c_{0}\right)+\frac{1}{3} \Delta a \Delta b \Delta c ; \\
& \Delta Y_{b}=\frac{1}{2} \Delta b\left(a_{0} c_{1}+a_{1} c_{0}\right)+\frac{1}{3} \Delta a \Delta b \Delta c ; \\
& \Delta Y_{c}=\frac{1}{2} \Delta c\left(a_{0} b_{1}+a_{1} b_{0}\right)+\frac{1}{3} \Delta a \Delta b \Delta c ;
\end{aligned}
$$

- чотирьохфакторної мультиплікативної моделі $Y=a \times b \times c \times d$

$$
\begin{gathered}
\Delta Y_{a}=\Delta a\left(b_{0} c_{0} d_{0}+\frac{b_{0} c_{1} d_{1}-b_{0} c_{1} d_{0}-b_{0} c_{0} d_{1}+b_{1} c_{0} d_{1}-b_{1} c_{0} d_{0}+b_{1} c_{1} d_{0}}{3}\right)+\frac{\Delta a \Delta b \Delta c \Delta d}{4} \\
\Delta Y_{b}=\Delta b\left(a_{0} c_{0} d_{0}+\frac{a_{0} c_{1} d_{1}-a_{0} c_{1} d_{0}-a_{0} c_{0} d_{1}+a_{1} c_{0} d_{1}-a_{1} c_{0} d_{0}+a_{1} c_{1} d_{0}}{3}\right)+\frac{\Delta a \Delta b \Delta c \Delta d}{4} \\
\Delta Y_{c}=\Delta c\left(a_{0} b_{0} d_{0}+\frac{a_{0} b_{1} d_{1}-a_{0} b_{1} d_{0}-a_{0} b_{0} d_{1}+a_{1} b_{0} d_{1}-a_{1} b_{0} d_{0}+a_{1} b_{1} d_{0}}{3}\right)+\frac{\Delta a \Delta b \Delta c \Delta d}{4} \\
\Delta Y_{d}=\Delta d\left(a_{0} b_{0} c_{0}+\frac{a_{0} b_{1} c_{1}-a_{0} b_{1} c_{0}-a_{0} b_{0} c_{1}+a_{1} b_{0} c_{1}-a_{1} b_{0} c_{0}+a_{1} b_{1} c_{0}}{3}\right)+\frac{\Delta a \Delta b \Delta c \Delta d}{4}
\end{gathered}
$$

Аналізуючи формули (17)-(19), легко переконатися, що для інтегрального методу виконується балансове співвідношення (7), тобто сума частинних абсолютних приростів дорівнює загальному абсолютному приросту $\Delta Y$. Причому додатковий приріст результативної ознаки, який виникає внаслідок взаємодії основних факторів, розподіляється між ними порівну.

Достоїнствами інтегрального методу слід визнати повне розкладання $\Delta Y$ за чинниками і відсутність необхідності встановлювати черговість їх дії. Але він має також й певні недоліки. До них можна віднести значну трудомісткість розрахунків навіть за наведеними робочими формулами, а також відсутність диференціації при розподілу додаткового приросту за факторами.

Метод логарифмування полягає в наступному. Відповідно до вихідного вираження (4) можна записати

$$
3_{Y}=\frac{Y_{1}}{Y_{0}}=\frac{a_{1} b_{1} c_{1} d_{1}}{a_{0} b_{0} c_{0} d_{0}}=\frac{a_{1}}{a_{0}} \times \frac{b_{1}}{b_{0}} \times \frac{c_{1}}{c_{0}} \times \frac{d_{1}}{d_{0}}=i_{a} \times i_{b} \times i_{c} \times i_{d} \text {. }
$$

Взявши логарифми лівої і правої частини співвідно-

шення (20), отримаємо

$$
\ln \left(i_{\mathrm{Y}}\right)=\ln \left(i_{a}\right)+\ln \left(i_{b}\right)+\ln \left(i_{c}\right)+\ln \left(i_{d}\right) .
$$

Якщо обидві частини рівності (21) розділити на $\ln \left(i_{Y}\right)$

i помножити на $\Delta Y$, то вона прийме вигляд:

$$
\Delta Y=\Delta Y \frac{\ln i_{a}}{\ln i_{Y}}+\Delta Y \frac{\ln i_{b}}{\ln i_{Y}}+\Delta Y \frac{\ln i_{c}}{\ln i_{Y}}+\Delta Y \frac{\ln i_{d}}{\ln i_{Y}} .
$$

Позначимо постійну величину $\Delta Y / \ln \left(i_{Y}\right)$ через $K$.

Тоді (22) остаточно представляється так:

$$
\Delta Y=K \ln \left(i_{a}\right)+K \ln \left(i_{b}\right)+K \ln \left(i_{c}\right)+K \ln \left(i_{d}\right)=\Delta \mathrm{Y}_{a}+\Delta \mathrm{Y}_{b}+\Delta \mathrm{Y}_{c}+\Delta \mathrm{Y}_{d}
$$


Формула (23) свідчить про те, що загальний приріст результативної ознаки $\Delta Y$ розподіляється за чинниками пропорційно логарифмам факторних індексів.

В даному випадку результат розрахунку, як i при використанні інтегрального методу, а також методу виявлення ізольованого впливу факторів, не залежить від місцерозташування чинників в моделі і в порівнянні з інтегральним методом забезпечує вищу точність розрахунків. Якщо при інтегруванні додатковий приріст від взаємодії чинників розподіляється порівну між ними, то за допомогою логарифмування результат спільної дії чинників розподіляється пропорційно частці ізольованого впливу кожного чинника на рівень результативного показника. У цьому полягає головна перевага даного методу. На відміну від інтегрального методу, при логарифмуванні використовуються не абсолютні прирости показників, а індекси їх зростання (зниження). Перевагою методу також вважається той факт, що при його застосуванні не вимагається встановлення черговості дії чинників.
Висновки та перспективи подальших досліджень. Аналіз достоїнств та недоліків кожного 3 методів показує, що не існує універсального підходу, який би задовольняв усім вимогам при розкладанні загального приросту результативної ознаки за чинниками при використанні в факторному фінансовоекономічному аналізі мультиплікативних моделей. При цьому метод ланцюгових підстановок має, на нашу думку, найбільш серйозні недоліки, пов'язані 3 викривленням впливу на $\Delta Y$ усіх факторів, окрім об’ємного.

Тому, ми рекомендуємо відмовитись від його застосування в факторному фінансово-економічному аналізі прибутку підприємства за допомогою мультиплікативних моделей i активніше впроваджувати в практику метод виявлення ізольованого впливу чинників, а також порівняно нового логарифмічного методу. Хоча проблема обгрунтування вибору між виокремленням ефекту взаємодії основних факторів або розподілу його між чинниками пропорційно логарифмам їх індексів остається поки ще відкритою.

\section{Література}

1. Методичні рекомендації оцінки впливу змін економічних факторів на результативні показники прибутку, рентабельності виробництва і реалізації продукції (робіт, послуг) / [Григор Н. М., Крехівський О. В., Ніколаєнко Н. Л. та ін.]. - К. : ДП ДІКТЕД, 2007. - 140 с.

2. Статистика : навч.-метод. посіб. для самостійного вивч. дисципліни / [А. М. Єріна, Р. М. Моторін, А.В. Головач та ін.]. - К. : КНЕУ, 2002. -457 с.

3. Статистика : підруч. / [С. С, Герасименко, А.В. Головач, А. М. Сріна та ін.]. - [2. вид., перероб. і доп.]. - К. : КНЕУ, 2000. - 467 с.

4. Янковий О. Г. Альтернативні моделі факторного індексного аналізу Матеріали 10-ї Всеукраїнській науково-практичній конференції «Статистична оцінка соціально-економічного розвитку». - Хмельницький, Хмельницький університет управління та права 2010. - С. 15-19.

5. Янковий О. Г. Детерміновані моделі факторного економічного аналізу. Методологія статистичного забезпечення розвитку регіону : Монографія / За заг. ред. А.З. Підгорного. - Одеса : Атлант, 2012. - С. 125143.

6. Осипов В. И. Методы факторного анализа и планирования в промышленности : [учеб. пособие] / В. И. Осипов. - К. : УМК ВО при Минвузе УССР, 1989. - 212 с.

7. Метод и методика комплексного экономического анализа хозяйственной деятельности [Электронный ресурс]. - Режим доступа : http://sumdu.telesweet.net/doc/lections/Ekonomicheskiy-naliz/16037/index.html. 


\author{
Чернышова О.Б. \\ кандидат экономических наук, доцент \\ кафедра финансов \\ Одесский институт финансов Украинского государственного \\ университета финансов и международной торговли \\ ул. 25 Чапаевской дивизии, 6, г. Одесса, Украина, 65070 \\ E-mail: chernyshova_o@ukr.net, \\ Янковой В.А. \\ кандидат экономических наук, старший преподаватель \\ кафедра экономики и управления национальным хозяйством \\ Одесский национальный экономический университет \\ ул. Преображенская, 8, г. Одесса, Украина, 65082 \\ E-mail:vladimir_ya@ukr.net
}

\title{
ТЕОРЕТИЧЕСКИЕ ОСНОВЫ ФАКТОРНОГО АНАЛИЗА ПРИБЫЛИ ПРЕДПРИЯТИЯ НА БАЗЕ ДЕТЕРМИНИРОВАННЫХ МОДЕЛЕЙ
}

Обсуждаются теоретико-методологические вопросы применения детерминированных моделей мультипликативного типа в процессе разложения абсолютного и относительного прироста прибыли предприятия по фракторам. Рассматриваются два основных класса мультипликативных моделей - статистические и математические. В частности анализируются методы цепных подстановок, выявления изолированного влияния факторов, исследуется диффреренциальный, интегральный и логарифмический методы. Проводится сравнение их преимуществ и недостатков, а также даются рекомендации по внедрению в практику финансово-экономического анализа на предприятии метода выявления изолированного влияния факторов и логарифмического метода.

Ключевые слова: детерминированные мультипликативные модели, метод цепных подстановок, метод выявления изолированного влияния фракторов.

Chernyshova O.B.

Ph.D. in Economics, Associate Professor

Department of Finance

Odessa Institute of Finance of Ukrainian State

University of Finance and International Trade

25 Chapayev Division str., 6, Odessa, Ukraine, 65070

E-mail: chernyshova_o@ukr.net

lankovyi V.O.

Ph.D. in Economics, senior lecturer

Department of Economics and Management of National Economy

Odessa National Economic University

Preobragenska str., 8, Odessa, Ukraine, 65082

E-mail: vladimir_ya@ukr.net

\section{THEORETICAL BASEMENTS OF FACTOR ANALYSIS BASED ON DETERMINISTIC MODELS OF COMPANY PROFITS}

The study of influence of individual factors on change of profit (loss) of the company used various models of relations, which by the nature of the cause-effect relationships that postulated between variables can be divided into two classes: deterministic and probabilistic. However, small samples probabilistic dependence between variables cannot be shown explicitly. This fact is the main reason for which these models 
almost not used in financial and economic analysis, as the researcher usually has information only 2-3 periods: during the reporting and the base (planned) year. Therefore, most used in financial and economic analysis of company profits gained deterministic models, including statistics (index) and mathematical models.

The theoretical and methodological issues of application of deterministic models multiplicative type in the decomposition of absolute and relative growth of company profits by factors discussed in this article. Among statistical approaches to factor analysis of profit considered two main classes of multiplicative models: based on the method of chain substitutions, and those through which detects the impact of isolated factors. In addition, relatively new mathematical methods of financial and economic analysis of profit - differential, integral, logarithmic - discussed in this article. A comparative analysis of their strengths and weaknesses, as well as specific recommendations for implementation in practice of the financial and economic analysis at the enterprise the most appropriate approach to identify the real impact of factors on output indicators - profits - has been made.

In particular, it is recommended to waive a factor of financial and economic analysis of profit chain substitutions method and related methods of absolute and relative differences as they all require priority consideration of the factors in effective sign and attach major factor interaction effect (synergistic effect) to the contribution of qualitative and structural factors. It threatens to distort the true essential role in shaping the specified factors increase effective signs.

According to the authors, method for detecting an isolated impact factors and logarithmic relatively new method should actively introduce the practice of financial and economic analysis. Although the problem of choosing between study the effect of interaction form the main factors or distribution of its proportional factors between the logarithms of indices still would remain open and require additional research.

Keywords: deterministic multiplicative model, the method of chain substitutions, the method of identifying the isolated influence of factors.

\section{References}

1. Hryhor N.M., Krekhivskyi O.V., Nikolaienko N.L. ta in. (2007). Metodychni rekomendatsii otsinky vplyvu zmin ekonomichnykh faktoriv na rezultatyvni pokaznyky prybutku, rentabelnosti vyrobnytstva i realizatsii produktsii (robit, posluh). K.: DP DIKTED, 140.

2. Yerina A.M., Motorin R.M., Holovach A.V. ta in. (2002). Statystyka: navch.-metod. posib. dlia samostiinoho vyvch. dystsypliny K.: KNEU, 457.

3. Herasymenko S.S., Holovach A.V., Yerina A.M. ta in. (2000). Statystyka: pidruch. K.: KNEU, 467.

4. Yankovyi O.H. (2010). Alternatyvni modeli faktornoho indeksnoho analizu. Materialy 10-yi Vseukrainskii naukovo-praktychnii konferentsii «Statystychna otsinka sotsialno-ekonomichnoho rozvytku». Khmelnytskyi, Khmelnytskyi universytet upravlinnia ta prava, 15-19.

5. Yankovyi O.H. (2012). Determinovani modeli faktornoho ekonomichnoho analizu. Metodolohiia statystychnoho zabezpechennia rozvytku rehionu: Monohrafiia Za zah. red. A.Z. Pidhornoho. Odesa: Atlant, 125-143.

6. Osypov V.Y. (1989). Metody faktornoho analyza y planyrovanyia v promyshlennosty : ucheb. posobye. K.: UMK VO pry Mynvuze USSR, 212.

7. Metod y metodyka kompleksnoho ekonomycheskoho analyza khoziaistvennoi deiatelnosty [Elektronnyi resurs]. Rezhym dostupa: http://sumdu.telesweet.net/doc/lections/Ekonomicheskiy-naliz/16037/index.html. 